\title{
RESTAURACIÓN - RECONSTRUCCIÓN - RECREACIÓN VIRTUAL APLICADA AL CONJUNTO RUPESTRE DE BACINETE
}

\author{
Virtual restoration - reconstruction - recreation \\ applied to the rock shelters of Bacinete
}

\author{
Mónica Solís Delgado ${ }^{1}$
}

Recibido el 1 de julio de 2009. Aceptado el 10 de septiembre de 2009.

Resumen. Se propone la restauración - reconstrucción - recreación virtual del arte rupestre prehistórico como alternativa económica y no destructiva a las intervenciones directas. Mediante montaje fotográfico, se pretende recrear el aspecto que debieron tener los emplazamientos con arte prehistórico en origen, a partir de un método inocuo, reversible y modificable.

Palabras claves: Bacinete, Laguna de la Janda, arte postpaleolítico, arte esquemático, restauración, reconstrucción, virtual, pintura rupestre.

Abstract. Virtual restoration - reconstruction - recreation of rock art would be an economical and non-destructive alternative to direct intervention. By using photomontage, an innocuous as well as reversible method, we expect to recreate how rock art sites would have looked like originally.

Key words: Bacinete, Laguna de la Janda, pospalaeolithic art, schematic art, restoration, reconstruction, virtual, rock paintings.

\section{INTRODUCCIÓN}

El arte prehistórico constituye una parte importantísima del patrimonio cultural de la humanidad, estaría incluido dentro de las creaciones artísticas inseparables de su soporte material, es decir, no es como la poesía que a pesar de ser también una obra de arte no es imprescindible el soporte sobre el que fue realizado, no hace falta el original.

Esto nos lleva a un grave problema, y es que la obra plástica está inevitablemente ligada a la materia mediante la cual se expresa, y la materia, como la experiencia nos muestra, tiende a modificarse con el paso del tiempo, por ello la obra plástica está inevitablemente condenada a la degradación. En concreto el legado artístico y cultural del hombre prehistórico debe ser entendido como patrimonio para toda la humanidad $y$, por tanto, cualquier medida que se emprenda debe serlo desde un riguroso control científico, teniendo como premisa fundamental la garantía absoluta de su conservación.

El arte rupestre prehistórico en la Península lbérica debido a la gran cantidad de emplazamientos existentes exige unas partidas económicas ingentes, que en el estado actual de las cosas es imposible conseguir, por ello adolece de cierta desprotección y abandono. Esta circunstancia se agrava en el caso de los abrigos decorados con pinturas al aire libre. Por un lado, muchos de estos emplazamientos con manifestaciones pictóricas no han sido aún estudiados y documentados, por otro su fragilidad dada su antigüedad hace peligrar

(1) Centro Asociado de la UNED en Madrid. msolis@madrid.uned.es 
su permanencia y como no las intervenciones antrópicas, en muchos casos vandálicas, han deteriorado gravemente algunas estaciones rupestres.

Se exige por tanto una alternativa válida y realista a la cuestión, un método que sirva para su documentación, autentificación, restauración y puesta en valor, pero que a su vez no elimine elementos que en un futuro puedan aportar datos esclarecedores al estudio de este patrimonio de un valor inestimable.

Partiendo de la problemática expuesta, la situación demanda el desarrollo de una técnica viable y realista, no sólo desde un punto de vista económico, sino también desde el tratamiento no destructivo de los emplazamientos. Para ello se hace necesario el desarrollo de un método de bajo coste que a su vez garantice la reversibilidad de los procesos y la inocuidad de los mismos.

\section{EL CONJUNTO RUPESTRE DE BACINETE. BREVE APROXIMACIÓN}

Para ilustrar la metodología empleada de manera clara y concisa, hemos considerado conveniente mostrar los resultados obtenidos de su aplicación experimental en el Conjunto Rupestre de Bacinete (Los Barrios, Cádiz).

Los abrigos se sitúan en Sierra del Niño, área incluida dentro de las unidades alóctonas del Campo de Gibraltar. La Sierra del Niño es junto a otras como Sierra Momia, Sierra Blanquilla o Sierra Sequilla... uno de los accidentes orográficos que rodean la depresión tectónica de la antigua Laguna de la Janda. Los terrenos en los que se encuentran los ocho abrigos decorados pertenecen al término municipal de Los Barrios. El grupo se localiza en la ladera suroccidental del Cerro Peruétano, cercano a la confluencia del río Ojén con el río Cañas dentro del Parque Natural de los Alcornocales.

En total son ocho los abrigos decorados que completan el conjunto; Bacinete I, II, III, IV, V, VI, VII y VIII o Gran Abrigo de Bacinete. H. Breuil y M.C. Burkitt (1929) en su obra Rock paintings of Southern Andalusia. A description of a Neolithic and Copper Age art group, lo califican como el más importante de toda la provincia de Cádiz después de la Cueva del Tajo de la Figuras (Benalup-Casas Viejas, Cádiz)

Por temática y estilo se sitúa en un contexto postpaleolítico y se adscribe estilísticamente al fenómeno esquemático. Los motivos pictóricos que aparecen se caracterizan por tratarse de representaciones en tonos rojos, más claro o más oscuro, esta matización de los tonos podría depender del grado de deterioro del pigmento. No se ha observado la presencia de grabados u otros tipos de técnicas presentes en el arte prehistórico.

Entre 1988 y 1993 se llevó a cabo el proyecto general de investigación arqueológica Las manifestaciones rupestres prehistóricas de la zona Gaditana, dirigido por Martí Mas Cornellà con la autorización y subvención de la Dirección General de Bienes Culturales de la Junta de Andalucia. En este proyecto se abordó el estudio de las manifestaciones prehistóricas de las sierras que bordean la antigua Laguna de La Janda, culminando con la publicación de Las manifestaciones rupestres prehistóricas de la zona gaditana (2000). En esta obra se someten a estudio, sobre todo, las manifestaciones rupestres situadas en Sierra Momia, pero en el proyecto se abordó el trabajo de campo de los emplazamientos decorados en Sierra del Niño, entre los que se encuentra el Conjunto Rupestre de Bacinete que quedó inédito a la espera del trabajo de gabinete. Este material inédito consistía en una detallada documentación fotográfica que amablemente fue cedido por el Dr. Mas Cornellà.

Entre 2004 y 2005 se llevó a cabo el trabajo de gabinete del material inédito, plasmado en nuestro trabajo de investigación de tercer ciclo El conjunto Rupestre de Bacinete, (Sierra del Niño, Los Barrios. Cádiz), en donde se realizó una primera aproximación al estudio de estas estaciones rupestres. El trabajo incluyó la realización de reproducciones digitales, la documentación detallada de los motivos pintados, así como análisis estadísticos y tipológicos.

En estos momentos estamos dando el paso siguiente, la restauración-reconstrucción-recreación virtual en aquellos motivos que su actual estado de conservación lo permiten.

\section{RESTAURACIÓN VIRTUAL. METODOLOGÍA}

En los últimos años hemos asistido a grandes avances en la introducción de complejos tratamientos informáticos de las imágenes para conseguir las reproducciones del arte rupestre prehistórico, alcanzando su máximo exponente en los "calcos digitales" mediante los programas de tratamiento fotográfico (Maura Mijares 2004). Hasta el momento estás técnicas han tenido como objetivo principal la documentación de los emplazamientos con manifestaciones rupestres prehistóricas a partir de una detallada documentación fotográfica digitalizada.

Aprovechando las amplias aplicaciones de estos programas, proponemos un paso más allá, la restauración-reconstrucción-recreación virtual mediante retoque y montaje fotográfico. Esta metodología se está desarrollando en campos como el diseño, publicidad, periodismo e incluso en la restauración de fotografía antigua. En este caso la intervención no se hace de manera directa, sino mediante montaje fotográfico. Se consigue así en un mismo proceso varios objetivos:

- Análisis preliminar de autentificación.

- Archivo fotográfico permanente de las manifestaciones, inmortalizándolas así ante posibles contingencias que se presentasen en el futuro. 
- Reproducciones digitales.

- Documentación y catalogación de motivos a partir de las reproducciones.

- Restauración-reconstrucción-recreación de motivos y paneles, mediante un método inocuo, reversible y modificable.

El proceso se ha realizado a partir de un material digital de altísima calidad, ya que para realizar las diferentes operaciones, siempre se han ampliado considerablemente las imágenes. El objetivo era que el proceso se asemejara al trabajo con microscopio.

Se han seleccionado las fotografías que tuviesen las mejores condiciones para posteriormente someterlas a un proceso de calibrado a partir de la escala IFRAO. Una vez realizada la calibración se ha intentado en la medida de lo posible no alterar las gamas de color, ni la saturación del pigmento, de este modo se procura realizar la acción sobre la fotografía corregida, sin alterar nuevamente los colores. El objetivo ha sido que la coloración del pigmento y soporte sea la más aproximada a la original, de esta manera se intenta que los resultados obtenidos de los diferentes procesos se acerquen a lo que debió ser el aspecto de las manifestaciones rupestres en origen.
Antes de realizar cualquier tipo de intervención, es imprescindible realizar el estudio detallado del emplazamiento, para ello se han realizado reproducciones digitales, análisis tipológicos, estilísticos y estadísticos, así como una pormenorizada recopilación de la bibliografía precedente. Es obvio que cualquier tipo de acción debe derivar del conocimiento exhaustivo del objeto de estudio, se dota así de rigor teórico a los resultados obtenidos. Aunque el proceso es indirecto, y por tanto, reversible e inocuo, hemos huido de cualquier propuesta que pudiera responder a una visión subjetiva, intentando así que los resultados se circunscribiesen a estrictos parámetros científicos.

\subsection{Restitución de pigmento}

El paso del tiempo y la situación de intemperie de las estaciones rupestres de Bacinete han provocado diversos tipos de deterioros y alteraciones. Tras la observación detallada de los motivos, se ha podido constatar la discontinuidad en trazos que en origen debieron ser continuos, esta situación se debe a desprendimientos de pigmento o craquelados. Para "reparar" estas pérdidas hemos restituido virtualmente el pigmento en estas áreas. El proceso se ha realizado mediante la clonación de pigmento adyacente, esté

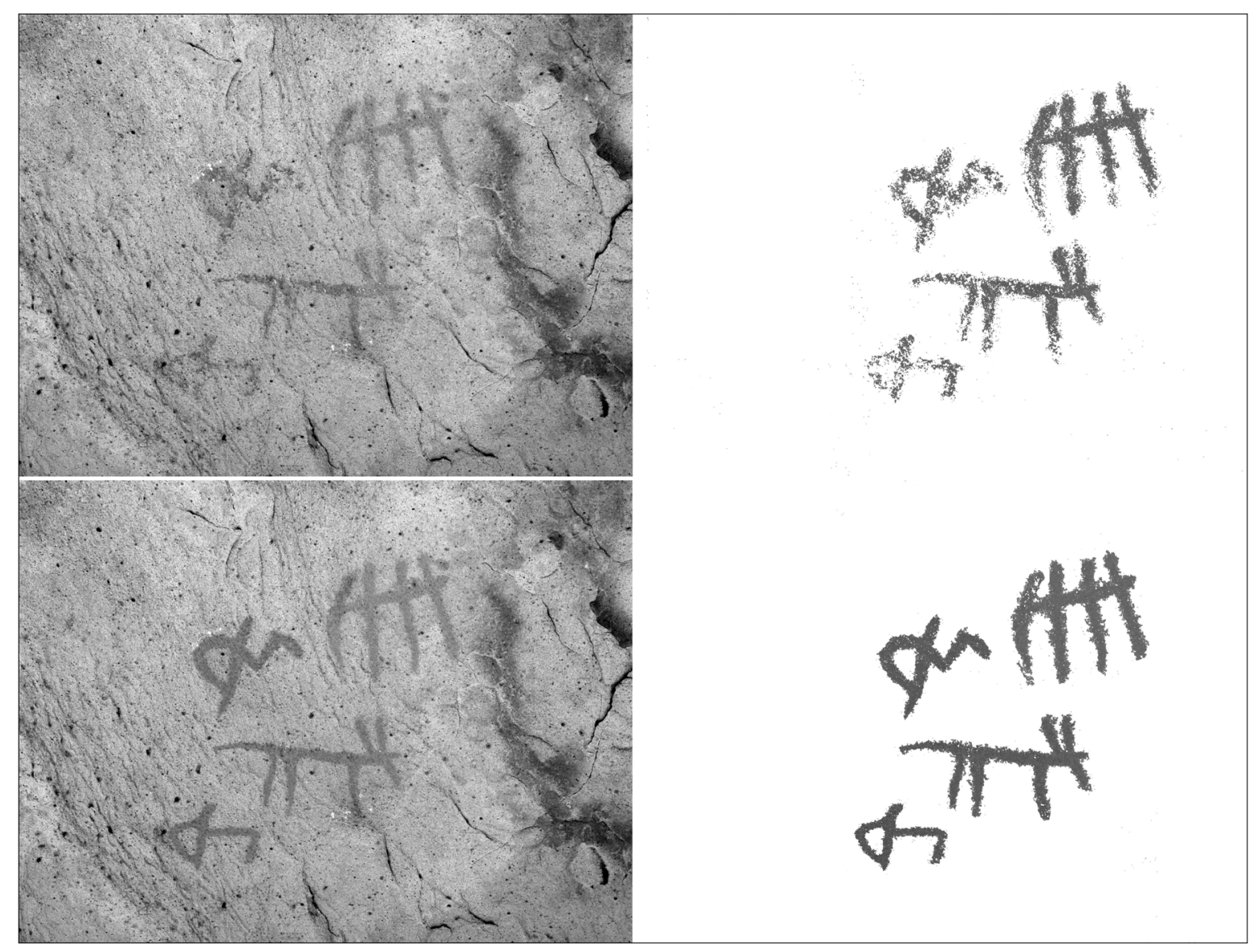

ه Figura 1. Motivos y calcos digitales del Gran Abrigo de Bacinete antes y después de la restitución de desprendimientos. 
método, aunque simple, mejora considerablemente la visibilidad de los motivos. Una vez completado el proceso, se han realizado los calcos a partir de la imagen sin retocar y de la fotografía restaurada.

\subsection{Corrección de la decoloración o degradación de pigmento}

Entre los tipos de deterioros observados destaca la degradación del pigmento que se evidencia en la decoloración del mismo. Esta situación ha provocado un desdibujamiento parcial o total en algunos motivos. Para recuperar estos tramos, se ha procedido a la clonación de pigmento en zonas donde la coloración del mismo se ha conservado en mejores condiciones, se logra así, que en estas áreas aumente la impregnación de la tonalidad y por tanto se le dota de mayor visibilidad a la figura. Siempre se intenta realizar la clonación en base a pintura original de tramos que se han conservado en mejores condiciones, y en la medida de lo posible se copia pigmento del mismo motivo en el que se realiza la intervención.

\subsection{Restitución de soporte}

Las tipologías de alteraciones y daños detectados en estas estaciones rupestres no afectan únicamente al estado de conservación de los pigmentos. El soporte rocoso de las manifestaciones ha sufrido también un deterioro progresivo.

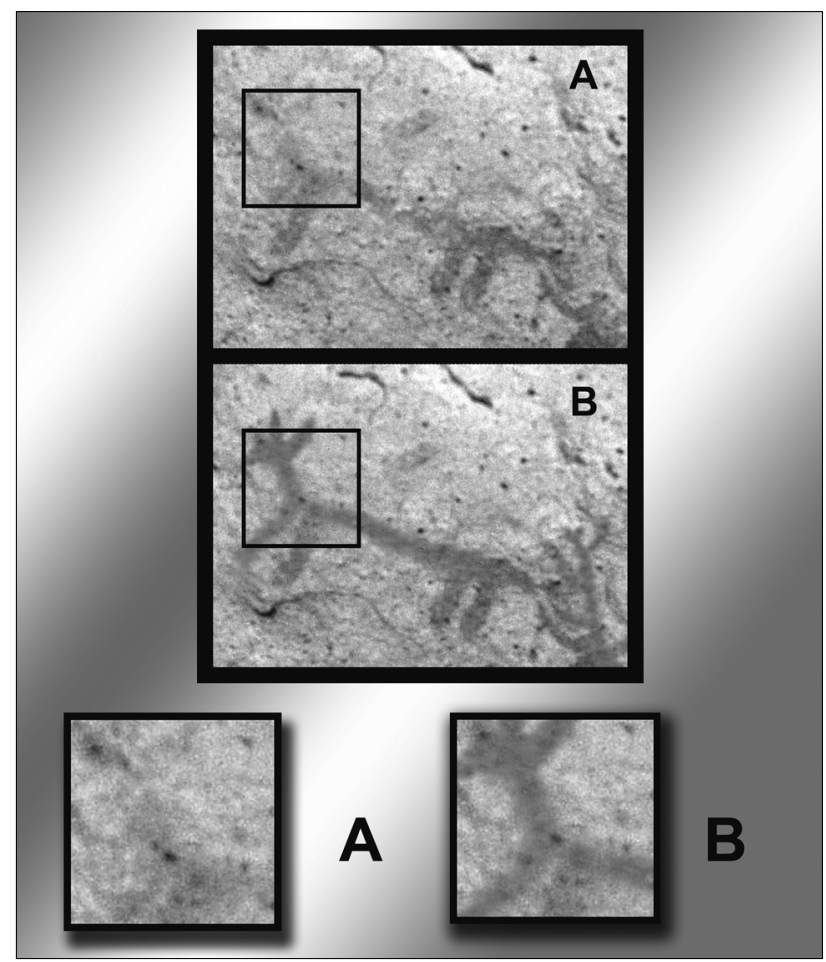

A Figura 2. Detalle de corrección de la decoloración de pigmento en un cuadrúpedo del Gran Abrigo de Bacinete.
Estos daños son, unas veces, de origen natural (desprendimientos, descamaciones, manchas producidas por microformaciones $u$ hongos...) y, otras, de origen ántrópico (humo

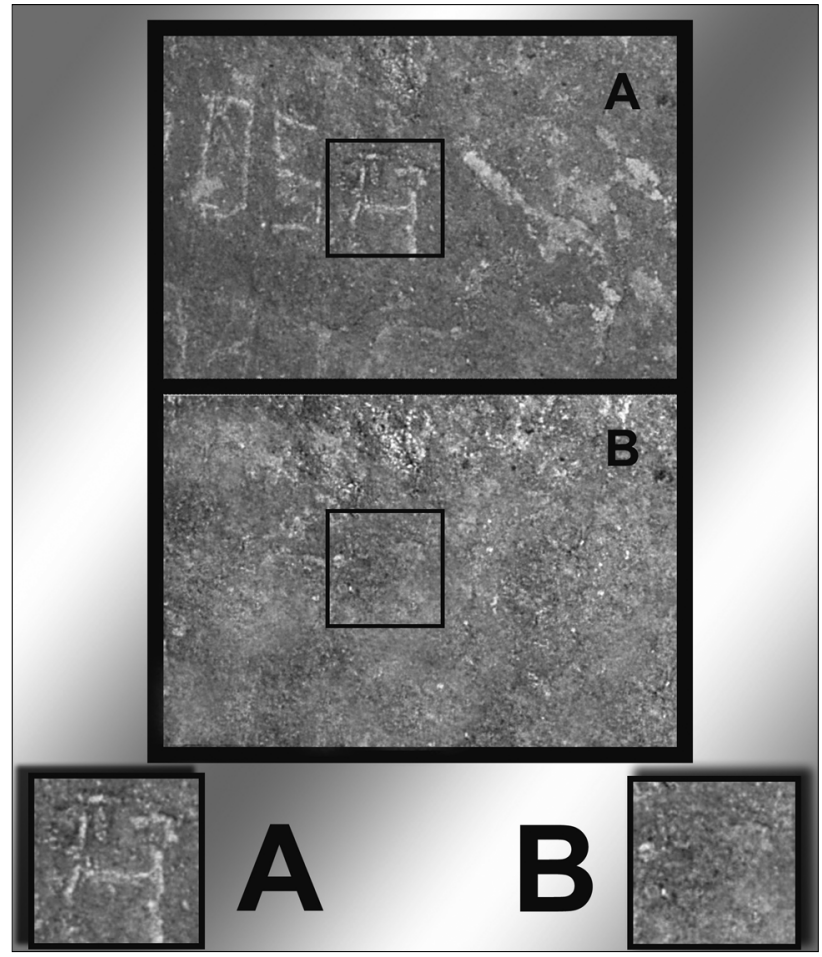

ム FiguRa 3. "Eliminación" de agresión antrópica en el soporte del Gran abrigo de Bacinete mediante restitución de soporte.

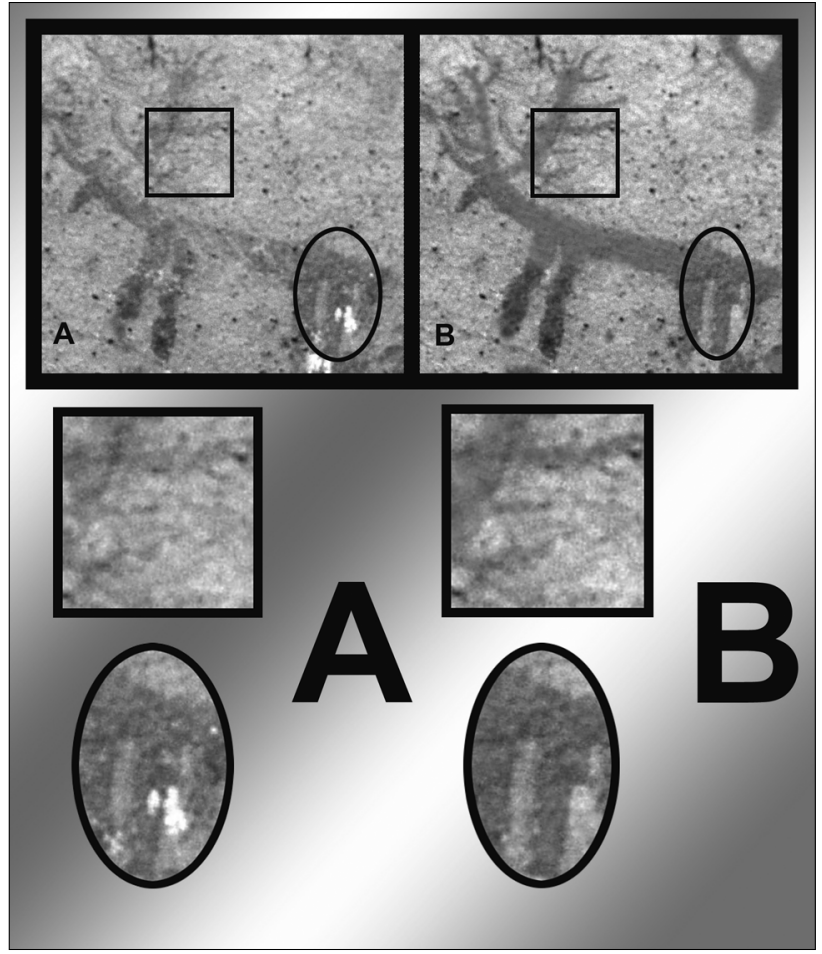

A Figura 4. Detalles de "limpieza" de soporte y pigmento en motivos del gran Abrigo mediante restituciones. 
adherido, pintadas o grabados de nuevo cuño...) Por esta razón se ha procedido en unos casos a la "reparación" de alteraciones, en otros a la "limpieza" de manchas y residuos adheridos al soporte. El tratamiento es semejante al aplicado para el pigmento, en este caso se realiza la restitución del soporte a partir de fragmentos rocosos no alterados. De esta manera se consigue una mayor visibilidad de los motivos, ya que en muchos casos permite apreciar mejor el contorneado de los mismos. Por otra parte, se eliminan grafías y alteraciones producto de actos vandálicos, se consigue así una imagen que intenta acercarse a la realidad de los emplazamientos en el momento en que fueron ejecutadas las pinturas.

\subsection{Corrección de la difuminación}

Tras la detallada observación de los motivos contenidos en el conjunto rupestre, se ha podido constatar que en algunos casos se ha producido un desplazamiento de pigmento de su posición original o difuminación. Este tipo de alteración se ha detectado en motivos principalmente situados en las partes bajas de las estaciones (es más que probable que se deba a la acción de frotación de animales) (Barroso Ruiz, 1991), hasta tal punto que la coloración se ha desplazado de su posición original, afectando el aspecto del motivo. Esta circunstancia se refleja en la desvirtuación del contorneado de las figuras. A través de una combinación de procesos

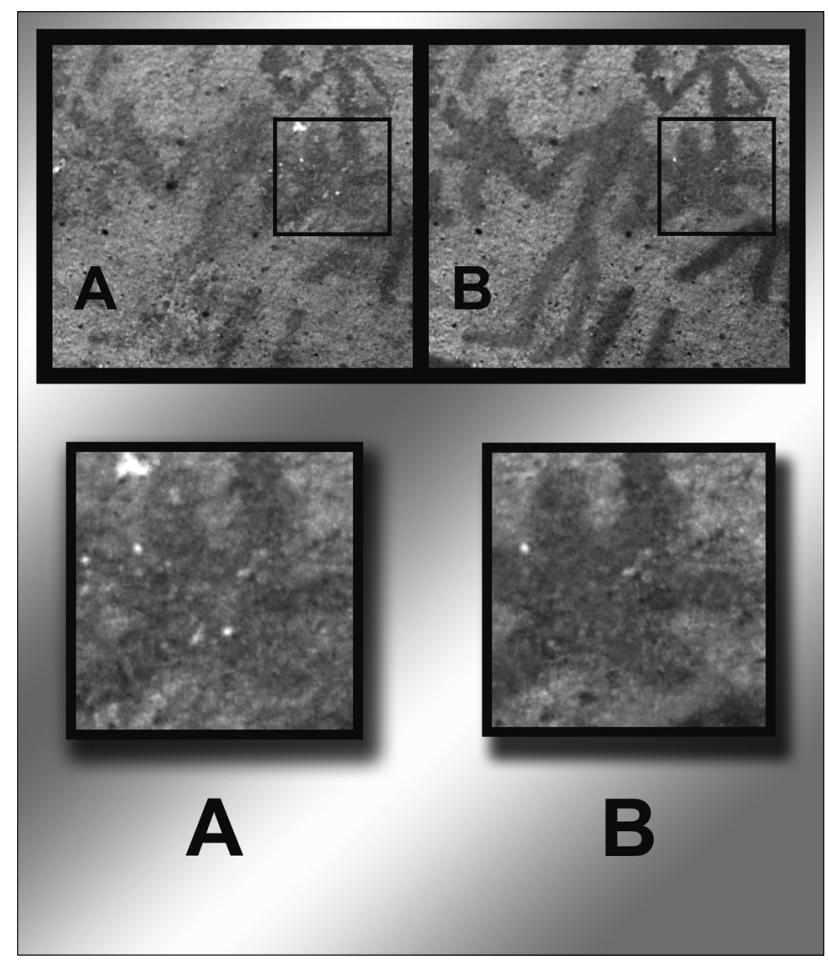

- Figura 5. Detalle de corrección del contorneado de un antropomorfo del Gran Abrigo de Bacinete. como restitución de desprendimientos de pigmento y soporte, eliminación de manchas y corrección de la decoloración de los motivos, se ha conseguido una mejor definición del aspecto que posiblemente tuvieron las manifestaciones rupestres tras su realización.

\subsection{Imposibilidad de intervención}

En algunas áreas, incluso en motivos completos, ha sido imposible la aplicación de los tratamientos anteriores, dado el grado de deterioro en el que se encontraban. La decisión de no intervención siempre se ha tomado a partir de una concienzuda observación del motivo y una relectura de la bibliografía precedente con resultados poco o nada esclarecedores. Cualquier propuesta hubiese resultado altamente cuestionable y escasamente científica, por tanto, se ha optado por no intervenir en los lugares en que cualquier tipo de acción responderia más a una interpretación subjetiva que a una aproximación documentada de lo que fue el aspecto de los motivos en origen. Aún tratándose de un método indirecto y por tanto reversible e inocuo, han primado criterios de rigor científico en todas las acciones emprendidas, en ningún caso se ha optado por ejercicios imaginativos o fantasiosos para obtener la recreación total de los emplazamientos. Todas las propuestas presentadas pueden aceptarse o rechazarse libremente, pero hemos tratado de huir de interpretaciones subjetivas carentes de criterio académico.

\subsection{CORRECCIÓN EXTREMA DE LA DECOLORACIÓN O DEGRADACIÓN DE PIGMENTO}

En algunas estaciones la coloración de las manifestaciones se ha perdido en gran medida, con lo que la contemplación de los motivos resulta extremadamente dificultosa. Para poder solventar este problema, se han tenido que someter a un proceso de impregnación de la pigmentación mucho más exhaustivo a los motivos más afectados. En estos casos la clonación de la pintura se ha tomado de un único fragmento del motivo. Tras una inspección exhaustiva de la figura a tratar, se ha elegido como muestra para la clonación la zona de pigmento que mayor impregnación conservaba, a partir de esta cata se ha corregido la decoloración de la totalidad de la representación. En muchos casos la referencia a clonar era de un tamaño extremadamente escaso, por lo que el resultado final del montaje puede resultar menos natural que en casos anteriores. Puesto que la intervención se realiza en el material fotográfico, no directamente en la obra, resultando en cualquier caso reversible e inocua, se ha optado por su realización, ya que nos aporta una mejora considerable en la visibilidad del motivo que será de gran utilidad para el estudio e interpretación del mismo. 


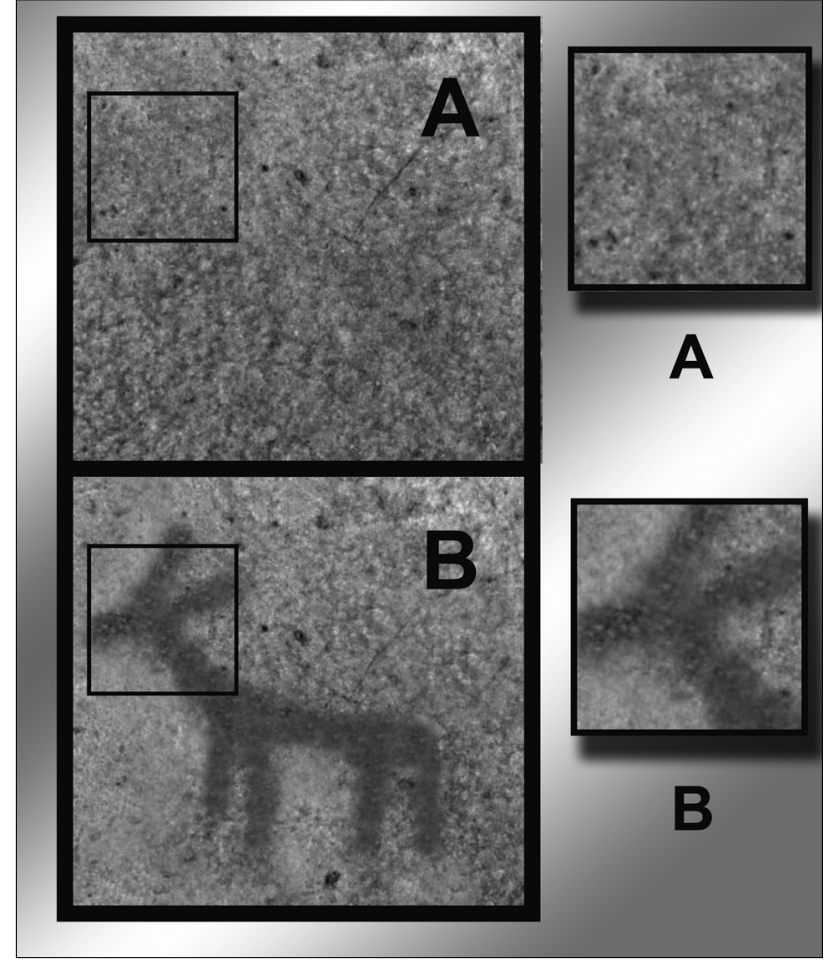

A Figura 6. Detalle de cuadrúpedo del Gran Abrigo de Bacinete sometido a un proceso exhaustivo de corrección de la decoloración del pigmento.

\subsection{Recreación-Reconstrucción}

El paso del tiempo y las agresiones antrópicas son factores capitales en el deterioro de los abrigos con arte rupestre. En las estaciones de Bacinete se han podido documentar motivos que han sufrido graves mutilaciones. Esta circunstancia nos hizo plantearnos la posibilidad de "reconstruir" o recrear virtualmente el aspecto que debieron tener estas manifestaciones antes de la agresión.

Para ilustrar este proceso hemos elegido el ejemplo de un motivo en Bacinete $V$ en donde las agresiones antrópicas han llegado a sus últimas consecuencias. El arranque de un fragmento de soporte ha provocado la pérdida de la mitad de una figura en phi griega. H. Breuil pudo documentar el motivo integramente, como se puede apreciar en su dibujo (A). La agresión afecta a la figura situada más a la derecha. Por otra parte, el pigmento ha sufrido un proceso de degradación progresiva debido al paso del tiempo (B). Para corregir esta situación degenerativa se han empleado dos acciones, por un lado, corrección de la decoloración del pigmento, explicado anteriormente (C), y por otro, una propuesta de "reconstrucción" del motivo y del soporte arrancado (D). Para ello nos hemos basado en la bibliografia precedente (Breuil, 1929) y en la propia morfología especifica del motivo. Se han incorporado trazos similares en coloración y grosor a los que se conservaban en la propia figura. Pero el proceso no se ha concluido en la propuesta de reconstrucción del motivo,

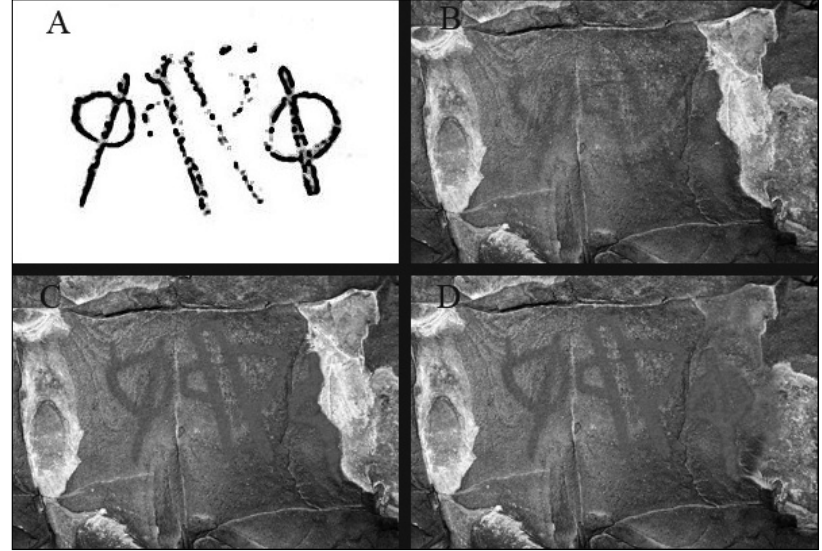

A Figura 7. Motivo mutilado en el Abrigo V.

también se ha aplicado al restablecimiento del soporte adyacente a la figura, se propone asi una imagen que pretende recrear al especto original que debió tener esta zona del panel.

\subsection{Combinación de procesos}

Hasta el momento hemos expuesto de manera individual las diferentes acciones utilizadas para obtener los montajes fotográficos. Es obvio que el proceso es mucho más complejo de lo explicado hasta el momento, ya que cada área del lienzo rocoso ha sido objeto de un detalla observación para evaluar que operación era la más adecuada en función del tipo de deterioro o degradación que presentase. Existen zonas en las que no se ha intervenido en modo alguno, motivos en los que sólo se ha aplicado una única acción y lugares que han necesitado el empleo de casi la totalidad de los recursos expuestos.

La combinación de las diferentes acciones explicadas ha permitido una mejora considerable tanto en la contemplación de motivos individuales como de paneles completos. El mejor ejemplo para mostrar los resultados obtenidos es la imagen de un tramo significativo del panel central del Gran Abrigo de Bacinete. En la misma podemos comparar la fotografía original con el montaje final en el que se han utilizado una compleja combinación de operaciones; reconstitución de fragmentos de pigmento desprendidos, limpieza de soporte, corrección de la decoloración de la pintura y mejora de la definición de los motivos.

\section{CONCLUSIÓN}

Los montajes fotográficos obtenidos mediante esta técnica aportan nuevos datos a la interpretación de nuestro pasado prehistórico a partir de sus manifestaciones. Por otra parte son aplicables a diversas acciones encaminadas a la 


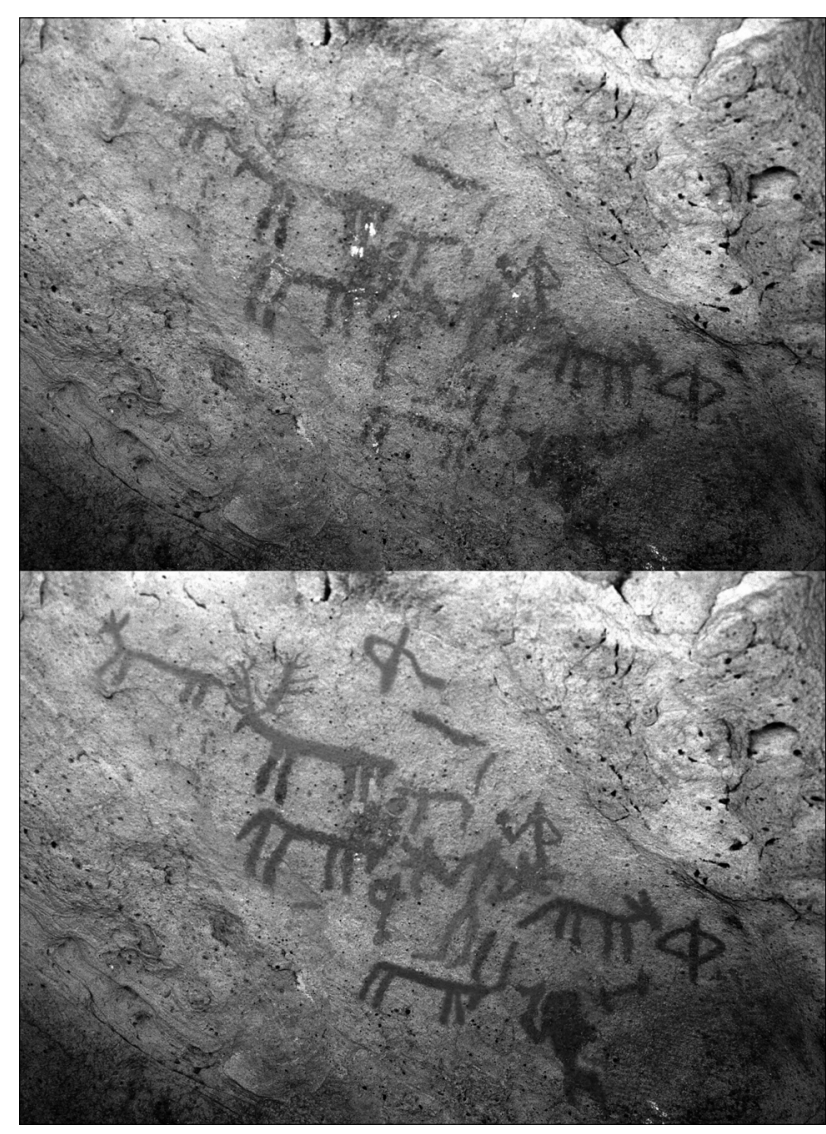

A FiguRa 8. Fotografía original y retocada del Panel de Bacinete VIII o Gran Abrigo. divulgación y puesta en valor de nuestros emplazamientos con arte rupestre, desde las más económicas (elaboración de panfletos, paneles y guías) a las más costosas (proyección de las reproducciones digitales de los paneles virtualmente restaurados sobre levantamientos topográficos Láser-Scanner 3D).

La restauración-reconstrucción-recreación virtual del arte rupestre prehistórico intenta aportar una metodología reversible e inocua a todos los emplazamientos con manifestaciones rupestres prehistóricas. Es nuestra responsabilidad desarrollar técnicas viables e inofensivas para todos los lugares que conserven manifestaciones de nuestro pasado prehistórico, con independencia de problemáticas económicas. Debemos garantizar además la reversibilidad de los procesos y la conservación de todas las evidencias que el paso del tiempo ha dejado sobre estas manifestaciones que muy probablemente sean susceptibles de ser estudiadas en el futuro.

Con los ejemplos que hemos expuesto podemos hacernos una idea de las posibilidades que el método ofrece. Que duda cabe que lo ideal serian unas intervenciones directas reales que garantizasen la conservación y restauración de las pinturas rupestres, pero abordando de un modo realista la cuestión es improbable que lleguen a todos los lugares. Por ello, hasta que se perfeccionen y abaraten las técnicas, proponemos una alternativa que al menos no prive en el futuro la aplicación de técnicas seguras y fiables.

\section{BIBLIOGRAFIA}

Amitrano, Bruno., 1985: Evolución y desarrollo de los criterios de restauración de la antigüedad al panorama actual. Revista de arqueología 47.

Arroyo del Rey, M., Gil Garcia, V. y Martínez de Salinas, E., 1997: Materialidad de las obras de arte. Estudio mediante métodos cientificos, Técnica y arte DYNA, 6, 93-102.

BARRoso RuIz, C., 1991: Investigación en el conjunto rupestre de arte postpaleolítico de Bacinete. Los Barrios (Cádiz). IV Jornadas de Arqueología Andaluza. Junta de Andalucía. Dirección General de Bienes Culturales. Sevilla, 49-54.

BERGMANN, Lothar., 2003: Arte sureño. El arte rupestre del extremo sur de la Península lbérica. AGEDPA. Cádiz.

BREUIL, H, BURKIT, M. C., 1929: Rock paintings of Southern Andalusia. A description of a Neolithic and Copper Age art group. Clarendon Press. Oxford.

BILLo, R. Y MARK, R., 2002: Aplicación del mejoramiento digital en las imágenes en la documentación de arte rupestre. Documentación y registro del arte rupestre: Actas de la sección 1 del V Simposio Internacional de Arte Rupestre, Septiembre 2000. Tarija, 142153.

CABRÉ Aguiló, J., 1915: El arte rupestre en España (regiones septentrional y oriental). Comisión de investigaciones paleontológicas y prehistóricas. Madrid.

-- y Hernández PACHeco, E., 1914: Avance al estudio de las pinturas prehistóricas del extremo sur de España (Laguna de la Janda). Comisión de investigaciones paleontológicas y prehistóricas. Madrid.
CABRERA ORTI, Maria Angustias, 1944: Los métodos de análisis Físico-químicos y la Historia del Arte. Universidad de Granada. Diputación provincial de Granada.

Carrasco Rus, J., Carrasco Rus, E., Medina Casado, J., Torrecillas GonzaLES, J. F., 1985: El fenómeno rupestre esquemático en la cuenca alta del Guadalquivir. I: Las sierras Subbéticas. Amigos de la arqueología Giennense. Jaén.

Castillo Requena, J.M., 1993: El clima de Andalucía. Instituto de estudios Almerienses. Almería.

FATAS, G. Y BORRAS, G., 1988: Diccionario de términos de arte y elementos de arqueología y numismática. Alianza Editorial. Madrid.

Gomez Gonzalez, M. L., 1994: Examen científico aplicado a la conservación de obras de arte. Ministerio de Cultura. Madrid.

Macarrón Miguel, Ana María., 1995: Historia de la conservación y la restauración. Tecnos. Madrid.

MAS CORNelLA, M., 1988: Las manifestaciones rupestres prehistóricas de la zona gaditana. 1988: Sierra Momia. Anuario arqueológico de Andalucía 1988. Actividades sistemáticas, informes y memorias. Dirección General de Bienes Culturales de la Consejería de Cultura y Medio Ambiente de la Junta de Andalucía. Sevilla.

-- 1989: Las manifestaciones rupestres prehistóricas de la zona gaditana. 1989: Sierra Momia y Valle del Río Cañas o Palmones. Anuario arqueológico de Andalucía 1989. Actividades sistemáticas, informes y memorias. Dirección General de Bienes Culturales de la Consejería de Cultura y Medio Ambiente de la Junta de Andalucía. Sevilla.

-- 1990: Proyecto de investigación arqueológica. Las manifestaciones rupestres prehistóricas de la zona gaditana. 1990: Reproducción y estudio directo del arte rupestre en Sierra Momia y Valle del Río 
de las Cañas o Palmones. Anuario arqueológico de Andalucía 1990. Actividades sistemáticas, informes y memorias. Dirección General de Bienes Culturales de la Consejeria de Cultura y Medio Ambiente de la Junta de Andalucía. Sevilla.

-- 1991: Documentación e investigación de las manifestaciones artísticas en la cuevas de Palomas, abrigos de Bacinete y conjunto rupestre del Tajo de las Figuras (Cádiz). Anuario arqueológico de Andalucía 1991. Actividades sistemáticas, informes y memorias. Dirección General de Bienes Culturales de la Consejería de Cultura y Medio Ambiente de la Junta de Andalucía. Sevilla.

-- 1992: El arte prehistórico en las Sierras del Campo de Gibraltar. Anuario arqueológico de Andalucía 1992. Actividades sistemáticas, informes y memorias. Dirección General de Bienes Culturales de la Consejería de Cultura y Medio Ambiente de la Junta de Andalucía. Sevilla.

-- 2000: Proyecto de investigación arqueológica. Las manifestaciones rupestres prehistóricas de la zona gaditana. Dirección General de Bienes Culturales de la Consejería de Cultura de la Junta de Andalucia. Sevilla.

JoRdÁ, J., CAMBrA, J., MAS, A., LombarTE, A., 1994: La conservación del Arte Rupestre en las sierras del Campo de Gibraltar. Un primer diagnóstico. Espacio, tiempo y forma. Revista de la Facultad de Geografía e Historia de la UNED. Serie 1, 7, 93-128.

Maura, R. y CAntalejo, P., 2004: La metodología aplicada en la Cueva de Ardales para la documentación del arte prehistórico, Actas de las Jornadas Temáticas Andaluzas de Arqueología. Sociedades recolectoras y primeros productores. Junta de Andalucia, 317331.

Montero Ruiz, I., Vicent Garcia, J. M., Cruz Berrocal, M. y Rodriguez AlCALDE, A. L. , 1998: Técnicas digitales para la elaboración de calcos de arte rupestre. Trabajos de Prehistoria, 55, 155-169.

Pascual Gonzalez, F., 2004: Guía de campo Adobe Photoshop CS y 7. Ediciones Ra-Ma. Madrid.

RAMIREZ, F. y otros, 1966: Introducción a los métodos de ensayos no destructivos. I.N.T.A. Madrid.

Solis Delgado, M., 2003-2004: El Conjunto Rupestre de Bacinete. Sierra del Niño, Los Barrios, Cádiz. Primeros resultados. Espacio, tiempo y forma. Revista de la Facultad de Geografía e Historia de la UNED. Serie 1, 16-17, 231-284.

-- 2004: El Conjunto Rupestre de Bacinete. Los Barrios. Una reflexión en torno al arte esquemático. Euphoros. Revista del Centro Asociado a la UNED del Campo de Gibraltar, 7, 93-108.

-- 2005: El Conjunto Rupestre de Bacinete. (Sierra del Niño, Los Barrios, Cádiz). Actas de las I Jornadas de Patrimonio en la Comarca del Guadalteba. "Arte rupestre con expresiones gráficas". Ardales.

TECAL., 1997: Ensayos no destructivos, técnicas radiológicas aplicadas a obras de arte. TECAL. Madrid.

TOPPER, U. y T., 1988: Arte prehistórico en la provincia de Cádiz. Diputación provincial de Cádiz. 